\title{
English Language Skills Training: Theory and Practice-A Cuban Perspective
}

\author{
Eddie Fisher \\ Faculty of Social Sciences, Universidad de Oriente, Santiago de Cuba, Cuba \\ Tel: 44-179-349-0423Ｅ-mail: eddie.fisher9@ btinternet.com
}

Jorge Luis Herrera Ochoa, Yoennis Diaz Moreno

Faculty of Humanities, Universidad de Oriente, Santiago de Cuba

Received: August 8, 2013 Accepted: August 26, 2013

doi:10.5296/ber.v3i2.7097

URL: http://dx.doi.org/10.5296/ber.v3i2.4097

\begin{abstract}
The ability to teach foreign languages effectively has become an increasingly important skill to develop and improve the language proficiency of students. Teachers need to develop and apply proactive and positive attitudes to foster new levels of foreign language learning within their students. Teaching, on its own, is not a panacea for success. This paper investigates how teachers at the Universidad de Oriente (UO) in Santiago de Cuba search for and apply innovative ways of teaching foreign languages to their students within current boundaries. The results from this research show that there is a positive relationship between the level of proficiency in a foreign language and the methods and approaches teachers apply to keep students motivated and interested in the subject matter. The literature review from this study provided supportive evidence which was strengthened with insights from face to face interviews and a focus group meeting. The outcomes confirmed that students, who are exposed regularly to practical and diverse teaching methods, are more likely to exceed the expected foreign language proficiency levels set by the UO's quality standards.
\end{abstract}

Keywords: English language teaching, Content and Language Integrated Learning (CLIL), Communications, Psychology, Language Teachers

\section{Introduction}

\subsection{Introduction}

Being able to communicate in a language other than one's own native language has become paramount not only in business but also in people's private lives. Many businesses operate in 
more than one country and people travel across the world to experience the different cultures of other people. Being able to communicate in another language brings people much closer together and much faster. Language teaching plays a vital role in developing and fostering people with the necessary attitude, motivation and driving force to become proficient in another language. This is not an easy task. Every person is different and responds in a different way to language teaching approaches and methods. Language teachers need to keep themselves informed of new technological advances, for example, to improve the effective and efficient means of teaching a foreign language to students. Some countries have been more exposed to the need to learn other languages depending on their geographical position and their economic situation, such as tourism being a major income provider. Europe, for example, has a long tradition of language teaching and language learning. Most European nations are close to each other or they are bi-or multi-lingual themselves such as Belgium or Switzerland. The need to communicate with one another across languages is therefore an old and obvious one.

Much of today's business discussions and negotiations are conducted primarily in English and many tourists use English as a common means to communicate with others in countries such as Cuba, Spain and Italy. The learning and teaching of foreign languages such as English, Spanish and German is of enormous importance across the world. It appears that publications on language teaching have often been seen as the lowest step of a staircase according to Appel (1995). At the top there is theory and as one walks down, the lower steps become more and more practical until class room interaction is reached. Practical applications in many and varied forms are what makes successful language teaching today. As knowledge methods of how to teach languages increase, so does the effectiveness of the end results. It appears that an emphasis on how languages are taught does not necessarily combine with changes in practice. Some teachers have shown a strong resistance to educational change. This has often been the subject of complaint. Some scholars such as Appel and Celik suggest that language teaching practice has been going on as if advances in research had never happened. The attitudes and associated behaviors of language teachers and Heads of Language Schools are of paramount importance. It is here where fundamental positive steps forward can be achieved.

One such forward-thinking institution is the Faculty of Humanities at the Universidad de Oriente (UO) in Santiago de Cuba. Language teachers of foreign languages such as English and German regularly review contemporary literature to keep up to date with the latest thinking in foreign language teaching methods. In addition, they conduct research via the Internet and by contacting language teaching institutions outside of Cuba to gather knowledge to make informed decisions to improve their own language teaching approaches. The UO currently teaches topics such as British and American History and Literature so that students learn about a new topic whilst at the same time improving their practical language skills, including linguistics and semantics.

Students have workshops and exams that provide opportunities to recycle the newly-gained knowledge. Early indications show that students perform better when the passing on of knowledge is approached in such a way that the level of motivation within students is 
increased noticeably and significantly. There is clear evidence that students enjoy and benefit from visits by foreign scholars who share their knowledge and experience in the appropriate language. These encounters are landmark points for the students as part of their training and development plan within the UO and their later professional/working life. For example, recent encounters at the UO included presentations and interactive class room discussions about topical business issues such as Conflict Management, Team Building and Effective Communications. These sessions are very intense and provide superior levels of learning over a much shorter period of time compared to regular classroom teaching. The use of equipment is limited to available resources but this does in no way limit the positive and proactive spirit of the teachers and the learners of new languages.

This research presents the outcomes of a study that investigated the close relationships between attitudes, behaviors and teaching competencies of foreign language teachers at the UO in Santiago de Cuba, how the students benefit from their proactive and forward-thinking teaching approaches and what the benefits are to the students in terms of increased levels of language proficiencies (Fig. 1).

\section{Language Teachers}

Positive Attitude
Positive/Proactive
Thinking
Topics of Interest
Motivates/Directs
Brings together Theory,
Practice and Context

Language Students

$\longrightarrow \begin{aligned} & \text { Benefit from new ways } \\ & \text { of teaching/learning } \\ & \text { Become comfortable } \\ & \text { in unfamiliar territories } \\ & \text { Their needs are met } \\ & \text { Well prepared for the } \\ & \text { 'real world' }\end{aligned}$

Language Proficiency

$\longrightarrow \begin{aligned} & \text { In Depth } \\ & \text { Highly Confident } \\ & \text { Any Time, any Place } \\ & \text { Professional } \\ & \text { Recognized } \\ & \text { High Demand }\end{aligned}$

Figure 1 The Relationship between Language Teachers, Language Students and Language Proficiency

\subsection{Literature Review}

According to Doernyei (2009), it will not come as a surprise to hear that language is a part of psychology. The reason for this is that language is not just a communications code or a cognitive linguistic system. Language is at the centre of everything human beings do, from the most prosaic to the most profound. It is the basic ingredient of virtually every social situation. Lightbown and Spada (2006) suggest that the acquisition of language is one of the most impressive and fascinating aspects of human development. It appears that the two fields of psychology and linguistics had the potential during the 1960s to work much closer together.

In contrast, Segalowitz (2001) considers that this opportunity never materialized. Segalowitz takes the grim view that "The sad truth is that many psychologists interested in language have not kept up with recent developments in linguistics and it would also seem that many linguists are not aware of what is happening in psychology, especially in cognitive psychology and 
cognitive neuropsychology" (p.4). According to Doernyei linguists and psychologists have looked at the same phenomenon from different perspectives. Accordingly, for example, teachers of languages tend to concentrate more on the descriptive rules and patterns of the language system such as grammar. Doernyei suggests that psychologists, on the other hand, focus more on the mental processes and structures whereby people understand, produce, remember, store and acquire the actual language.

Belyayev (1965) considers that students who learn a foreign language must by force of necessity learn to think in that language. Consequently, the whole process of language teaching is to be envisaged as the switching of the student's thinking from one language to another. Belyayev asserts, based on some research, that once students have mastered a foreign language, the learner does not need to revert back to his native language to use the resources of that tongue. The learner has acquired the ability to think directly in the new foreign language he/she has learned. According to Belyayev (1969), based on some further research, language teachers have an important role to play in the effective teaching of foreign languages. Belyayev considers that thinking in a foreign language reveals specific characteristics and presents certain distinctive features in relation to thinking in the native language. This is why language teachers need to master the art and means of communication in a foreign language so that the language student evolves a different way of thinking. Belyayev did not elaborate on what he meant by "thinking". Littlewood (1981) considered earlier that communicative activities are paramount to the successful learning of another language. He defines communicative learning as an activity whereby the student engages in activities with the main purpose of communicating meanings effectively to another student or the teacher. Littlewood suggests a number of contributions that communicative activities can make to language learning. For example, whole task practice is a structured approach in order to suit the learner's level of ability. This integrates all of what has been learned so far. Littlewood asserts that learners want to participate more in communications with others and are therefore more motivated to learn much faster. The actual use of the new language is also an important part of the total learning process. Natural learning is a result of applying, for example, in conversations what has been learned. Communicative activities create environments that support the individual in their efforts to learn.

Lynch (1996) suggests that it is important that teachers observe how foreign language students succeed or fail in their efforts to communicate in the classroom or language laboratory. It can help them to intervene to make learners' use of the foreign language more effective. Teachers should never be afraid to search for new teaching techniques and approaches to improve the effectiveness of language teaching. Some methods may well work better in some settings such as rural schools or Universities but of paramount importance is to have the right attitude to at least try some new way of teaching.

Teachers should always try out something themselves so they can use this practical experience to argue in favor of any desired approach changes. Lynch points out that students should be encouraged to interact through classroom tasks such as presentations and group exercises by using the traditional language skills of listening, reading, speaking and writing. Comprehension plays an important role in the development of the foreign language learners' 
competence in that language. As part of the teaching process, teachers of foreign languages must develop the active listening skills of students. To become competent in another language involves much more than just recognizing what is being said. Comprehension is multi-layered and requires or allows interpretation at different levels. When people, for example, listen to their own language, they often go beyond the input in many ways. This is where language schools can provide learners with appropriate help. Research has shown that low-level learners tend not to use the effective listening strategies that they would apply in their first language.

Lynch quotes Krashen (1985) who argues that under suitable affective conditions such as positive feelings and motivation, language learners will use some parts of this input not only to comprehend the current message but also to pick up new items of grammar and vocabulary and to improve their fluency in speaking. Interactive negotiations are an effective route to improve language proficiency. Lynch considers that language teachers play a vital role in the effective teaching of foreign languages to students. Teachers, based on years of practical class room experience, recognize the important link between comprehension and progress in a foreign language and then design classroom teaching appropriately. This includes the effective utilization of tools such as the language laboratory and inviting native English speakers to interact with students. Krashen reports that it is the teacher's personal style that makes a fundamental difference how students pick up language skills, for example, by how they ask questions. This has a major impact on how students learn. Krashen asserts that those teachers' abilities to close the gap between the students' perception what the teachers are trying to focus on and what they actually are focusing their attention on is of paramount importance to the effective teaching of a foreign language. The authors, based on years of practical classroom teaching in foreign languages, suggest that regular interactions with native speakers of languages provide students with opportunities to acquire and use, for example, new vocabulary, grammar and contemporary expressions and phrases in the relatively safe environment of the classroom. Native speakers of languages must modify their speech content to ensure that the messages sent are received as intended.

According to House (2008), language is the most important means of communicating, of transmitting information and providing human bonding. It is a person's prime means of acquiring knowledge of the world, of transmitting mental representations and making them public and inter-subjectively accessible. House considers that language per se has an influence on its speakers' thinking, their world view and behavior. This is in contrast of the view that language "reflects" the culture of a social group. House suggests that some people have acquired language proficiency in more than one language.

This is the kind of person who has been exposed to, for example, the language intricacies of his own native tongue and those of another language. Such a person has the potential to develop "his or her own third way, based on the combined knowledge and experience of more than one native language" (p.19). This puts students into a precarious position but ultimately one of enrichment. Such experiences offer the intercultural speakers deeper insights and understanding in both cultures (own and learned). It appears that English is the preferred option for linguistic unity, allowing people from different first language backgrounds to communicate (Soler, 2008). As a consequence, nearly all Europeans, irrespective of social class, are provided 
with instructions in English. The language is also accepted as an international or global language. It should be noted that the following statements are not questioned and some are perhaps the fundamental reason why so many students across the world study English at University level:

-English is the language spoken by more non-native speakers than native speakers

-English is the language to have access to journals and conferences

-English is the dominant language in publishing

-English is used when the content of courses, manuals and software have a bilingual or trilingual pattern

-Multinationals are set up in Europe and irrespective of their location, English is the working language

-English language education is compulsory in most schools

House suggests that when English is used in mutually occurring contexts, then the outcome will be much stronger and more relevant for its intended use. Frydryclova Klimova (2012) reports that the European Union (EU) emphasizes that Content and Integrated Language Learning (CLIL) in which pupils learn a subject through the medium of a foreign language, has a major contribution to make to the Union's language learning goals. It can provide effective opportunities for pupils to use their new language skills now rather than learn them now for use later. It opens doors on languages for a broader range of learners, nurturing self-confidence in young learners and those who have not responded well to formal language instruction in general education. It provides exposure to the language without requiring extra time in the curriculum which can be of particular interest in vocational settings. The introduction of CLIL approaches into an institution can be facilitated by the presence of trained teachers who are native speakers of the vehicular language. The authors consider in this context that the example of the EU is relevant to this research as many languages are spoken within the current member states of the EU. The combined learning knowledge and experiences from Europe are relevant and should be taken into consideration as it is suggested that these can be applied universally, subject to local prevailing cultural differences.

Hismanoglu and Hismanoglu (2011) consider that, based on the constructivist theory of learning and communicative language teaching methodology, the task-based viewpoint of language teaching has emerged in response to some constraints of the traditional Presentation, Practice and Performance (PPP) approach (Ellis, 2003; Long and Crookes, 1991).

It has the significant meaning that language learning is a developmental process enhancing communication and social interaction rather than a product internalized by practicing language items, and that learners master the target language more powerfully when being exposed to meaningful task-based activities in a natural way. It was in the 1980s that this viewpoint of language learning gave rise to the popularity of various task-based approaches (Breen, 1987; Candlin and Murphy, 1987; Nunan, 1989; Prabhu, 1987). Moreover, during the 1990s, it developed into a comprehensive structure for the communicative classroom where learners did 
task-based activities via cycles of pre-task preparation, task performance, and post-task feedback via language focus (Skehan, 1996). According to Ellis (2003) task-based language teaching has been re-investigated recently from a variety of perspectives covering oral performance, writing performance and performance assessment.

Celik (2013) holds the view that course instructors across a wide range of disciplines such as language teaching, have implemented computer-based learning resources such as online discussion boards. Celik suggests that the benefits of implementing an online discussion board in teaching have been well-documented and that an investigation into the social aspects of online learning environments is still needed in order to develop a deeper understanding of how group dynamics affect the overall learning experience. Celik conducted a related action research project that explored the perceptions of graduate students concerning the use of an online discussion board that revealed that positive group dynamics appeared to be prevalent in the discussion. In contrast, the perception of the individual class members did not always agree with this view. The authors consider that that outcomes of Celik's discussion board project could be of value to students with disparate levels of knowledge of a foreign language as the cumulative learning effect would be of benefit to students, irrespective of their levels of proficiency.

The literature review from this research suggests that there is a gap between contemporary language teaching approaches and methods and what language teachers could achieve if they adopted new and different approaches to develop the language proficiencies of their students. Established subject matter experts consider that it is the appropriate application of different language teaching approaches and methods that can make it possible for language teachers to improve the foreign language proficiency levels of their students significantly.

\subsection{Main Research Questions/Hypotheses}

The following research questions were constructed:

1. What is the value of presenting topics of interest by visiting native English language practitioners who use contemporary English that is used in business and academic environments?

2. What is the value to English language teachers of conducting regular research in order to keep abreast of the latest thinking in language teaching approaches and methods?

3. Does the power distance between English language teachers and their students affect the quality and proficiency levels of the learning?

The following hypotheses were constructed:

H1: English language students improve their English language proficiency substantially if they interact regularly with business people and academics whose native language is English

$\mathrm{H} 2$ : English language teachers improve the quality of their teaching in the classroom for the benefits of students if they develop a positive and proactive attitude towards contemporary foreign language teaching methods and tools 
H3: English language teachers who give students the freedom to learn and practice using their own chosen topics are increasing students' self-confidence and speaking abilities of speaking in the foreign language substantially

\section{Research Methodology}

\subsection{Method}

The authors applied a constructivist interpretivist research approach within a phenomenological research paradigm. They considered that this was most appropriate in order to make a valid and reliable contribution to knowledge. The outcome of this research is applicable to both academics and practitioners. The aim and purpose of this research, in line with the research questions and hypotheses from Section 1.3, are to suggest what makes an effective and efficient language teacher based on the work that has already been done at the UO in Santiago de Cuba and what is planned in future. It is important that foreign language teachers can experience new approaches and methods themselves to confirm that these are valid and reliable. The authors consider that the change in expectations to develop new tools and techniques for teaching foreign languages (Section 1.1) is the likely reason why foreign language teachers are under increasing pressures to respond to these new demands in a proactive and positive manner. Thirteen final year undergraduate students from the Faculty of Humanities and thirty-three undergraduate students from the Faculty of Social Sciences of the Universidad de Oriente (UO) in Santiago de Cuba were interviewed by the authors during face to face and focus group meetings. The authors who have over 50 years of theoretical and practical work experience were acting as participatory observers to facilitate this research. The interviews were conducted in early 2013 in Santiago and recorded verbatim to ensure that all responses were captured correctly, including meaning as intended. Interviews were semi-structured. Participants' ages ranged from 19 years to 24 years and they had between three and four years of practical work experience of applying foreign language skills acting as translators and interpreters. The participants were asked for their insights to answer the main research questions from Section 1.3, using their own theoretical and practical experiences from the past and the present.

Table 1 is a summary of the questions that were asked during the face to face and focus group meetings. The first objective of the face to face interviews was to review the outcome of the literature review and confirm whether the research data from the literature review was relevant and admissible as evidence for this research. The second objective was to consider how language teachers need to apply these kills in a practical way in classroom situations and to confirm what makes an effective foreign language teacher. The purpose of the focus group was to review the contributions the individuals made during the face to face meetings, in a group environment, to check whether these findings, together with the outcome from the literature review, could be verified and improved. The focus group reviewed and checked the findings from the literature review and the face to face interviews and made final recommendations that would be of practical value to suggest what makes an effective foreign language teacher and what the associated teaching approaches and methods are.

Table 1. Research Questionnaire: Practical Language Skills Teaching 
1. What is your definition of Language Skills Teaching?

2. What are the aspects you associate with effective language skills teaching?

3. What is your view on the claim that the concept of practical language skills teaching is a desirable and effective methodology?

4. What potential problems do you associate with practical language skills teaching?

5. What are your personal practical experiences with practical Language Skills Teaching -give some real life/practical examples/feedback on the course

Why did it work for you?

Why did it not work for you?

\subsection{Data Collection, Interpretation and Triangulation}

The authors applied three methods to collect relevant research data to answer the main research questions and hypotheses from Section 1.3: a review of the literature (Section 1.2), face to face interviews (Section 3.1) and a focus group meeting (Section 3.2), within the context of a phenomenological research paradigm and an associated constructivist interpretivist research approach. The authors were thus able to get closer to the subject matter under investigation. They have added their own interpretations of what makes an effective foreign language teacher and associated teaching approaches and methods, in their role as participant observers. This research approach allowed for the collection of different perceptions of the phenomena under investigation. All research data was collected over a period of three months. The authors applied triangulation as a means to use a combination of different methods in order to reduce reliance on a single research method and to ensure that the use of all data was consistent and coherent.

\section{Results}

\subsection{Face to Face Interviews}

Thirteen final year undergraduate English language students and their teachers from the Faculty of Humanities placed a high importance on the attitude and abilities of foreign language teachers to make language teaching in the classroom and laboratory interesting and exciting. They considered that it is not the syllabus in itself that will lead to the successful teaching of foreign languages but how teachers interpret the syllabus and how they consider and develop new methods of effective teaching. To have detailed knowledge of a subject matter such as English language is no panacea for success. It is the teachers' personal ability to engage with language students in an interesting, motivational and exciting way that will make all the difference. The authors, based on many years of practical language teaching in classrooms, consider that students learn much better if different teaching approaches are applied as this allows different levels of immersion in the language. The students considered that the four linguistic skills of reading, writing, listening and speaking are still valid but that it is the practical application of these that will make a substantial contribution how quickly and how effectively students learn foreign languages. All participants insisted that real names should be used to give this research authenticity. Individual interviews were conducted with the students 
who considered what they associate with effective language skills teaching and what effective teaching methods should be applied to improve the long-term proficiency in a foreign language such as English:

1. What is your definition of Language Skills Teaching? "It means teaching the language by dividing the teaching process into the different skills of the language: reading, writing, listening and speaking" (Yeynier; Anelis). "The teaching of language skills is the implicit teaching of separate language skills in order to help the student achieve the proper competence in the language" (Maikel). "Language skills teaching is the teaching of a foreign language dividing the content into the four linguistic skills and at the same time combining it into one major skill or competence" (Clara). "It is about the teaching of a foreign language in respect of the language's idiosyncrasies through the methods of reading, writing, speaking, listening and other sub skills" (Manuel).

2. What are the aspects you associate with effective language skills teaching? "Teaching language skills in an effective way requires teaching the content the students actually need at the time and thus motivate them to study the language in an accurate way" (Lianne)." To teach language skills effectively the teacher must be well prepared in the proper methodology to teach each of the skills separately and all in tandem. Besides, a key factor is the inclusion of real life situations in the teaching learning process2 (Alberto)." A skilled language teacher should combine all the content of the four skills so that the students learn the four skills in tandem and thus develop the required language competence" (Roberquis)." An efficient and proficient teacher would integrate the content of the four skills in his/her lectures and would also raise students' awareness of the importance of the four linguistic skills as well as provide a positive feedback"(Fernando).

3. What is your view on the claim that the concept of practical language skills teaching is a desirable and effective methodology? "The concept of practical language skills teaching is quite relevant in the training of language students. Students will get the language and the culture of the source language as well" (Fernando). "It is so because it enables teachers to prioritize the elements of language skills they would like to concentrate on" (Lisbet). "It is effective for people above a basic level and a faster way to learn the language for immigrants or academic applicants" (Manuel).

4. What potential problems do you associate with practical language skills teaching? "The potential problem would be for beginner learners; this approach is more suitable for intermediate and advanced students who have more background to acquire vocabulary and grammar rules in this way" (Yeynier).

"Using the practical language skills teaching approach would probably be a problem for it alone would not cover all the aspects that the students need to properly learn a language " (Lianne). "Practical language-skills teaching should not present problems but with the grading of the content to be taught which should be suited to the student's needs "(Maikel).

"Practical language skills teaching should not be used on its own. It should be combined with 
other methods to achieve the required level of competence "(Fernando).

5. What are your personal practical experiences with practical Language Skills Teaching -give some real life/practical examples/feedback on courses you attended. Why did it work for you?

Why did it not work for you? "Personally, I have noticed that it is much easier to learn this way, for instance, when I was a student, I spent two years studying English language and then during the third year we had lectures about British history where I learned new historical facts but at the same time you unconsciously learn new grammar rules and vocabulary along with the pronunciation and contextual usage of the words; that is what makes it work, it is easier to remember grammar rules and vocabulary in this way than it would be learning random words and rules " (Yeynier). "In my experience practical language skills teaching is quite useful. It is easier to practice what you have learned when you practice it in that way. This kind of knowledge is easier to remember and closer to real life situations "(Lianne). "Practical language skills teaching has proved relevant to me because my students seem to enjoy it more and at the same time they remember the things learned more easily, which makes it a win-win situation for both students and teachers " (Daniel). "The concept of practical language skills teaching has always been useful to me but combining it with other methods. I have always used to support the rest of the classes and it has had excellent results for me when I take other subjects, somehow related to the content of the semester, and use them in practical language skills lessons" (Fernando). "I have worked with videos and I have integrated the other skills with them. The course helped a lot. I was great to realize that what I have been doing for a few years was not crazy at all "(Lisbet).

The authors assert that the contributions from the community of practice have been invaluable to the drive to answer the main research questions and hypotheses from Section 1.4. All students have been engaged in applying their acquired English language skills during simultaneous translation sessions during academic and business presentations held at the UO over a period of time. This provided them with valuable opportunities to apply in real life what they learned in the classroom and language laboratory environments and to validate and review the English language teaching approaches currently employed at the UO. These insights have strengthened the presentation of the qualitative data from this research and provided important inputs to the presentation of the analysis and interpretation to emphasize the qualitative nature and to the constructivist interpretivist research approach of this current research. The inputs from the community of practice and the authors' own extensive experiences have provided important insights and contributions to develop and suggest what the effective approaches and effective English language teaching skills are within a proactive thinking and acting language department at the UO in Santiago de Cuba.

\subsection{Focus Group Meeting}

This focus group was made up of the same thirteen final year undergraduate students from the Faculty of Social Sciences at the UO that were interviewed individually during the face to face interviews. Attendees were familiar with best practice in English language teaching. This was reinforced by the authors through a series of short presentations prior to the start of the formal discussions to set the scene for the focus group meeting. The focus group checked and 
validated the reliability of the research data from the literature review and the face to face interviews. The focus group confirmed that the research data from the literature review was consistent and admissible. The focus group associated the infusion of presentations from a native English speaker with improving language skills in a number of areas. They felt that a regular exposure to native English speakers, for example, enhances their vocabulary in topical areas such as Project Management, Intercultural Communications and Negotiation and Persuasion. This learning is reinforced by drawing on the practical knowledge and experience of guest speakers. They suggest that topical presentations by external native English speakers should be incorporated into English language degree program syllabuses. It should be noted that this applies equally to all other language programs at the UO. The same research questions from the face to face interviews were used in the focus group meeting:

1. What is your definition of Language Skills Teaching? "The teaching of language skills means teaching a foreign language in an organized way by dividing the content into the four linguistic skills of listening, speaking, reading and writing" (Jorge, Yoennis). "Language skills teaching is the teaching of a foreign language dividing the content into the four linguistic skills, and at the same time combining it into one major skill or competence" (Clara).

2. What are the aspects you associate with effective language skills teaching? "An effective language skills teaching would include all the skills not only in a theoretical way but also in a practical and contextual way" (Yeynier). "In order to teach language skills effectively the teacher must reach a synergy between the four skills making the content as close to real life as possible, so that the boundary between each skill is nearly imperceptible" (Jorge, Yoennis). "To teach the four skills in a proper way the teacher must grade the data according to the level and needs of the students, keep the students' attention focused on the subject matter and encourage the students to further their studies by means of positive feedback" (Daniel).

3. What is your view on the claim that the concept of practical language skills teaching is a desirable and effective methodology? "In my opinion practical language skills teaching is indeed a desirable and viable way to teach a language because the learners acquire knowledge in a more ample and contextual way- for example, they learn new vocabulary and grammar in a given context which makes it easier to remember and put into practice later" (Yeynier).

"Practical language teaching is a good approach both for the student and the teacher because it implies teaching vocabulary and grammar rules without directly focusing on them" (Jorge, Yoennis). "The practical teaching of a language is a very effective method for it involves being more interactive and at the same time teaching more than just language" (Alberto). "The teaching of practical language skills is very useful. It combines all the skills into one and soothes the teaching learning process. It is also a powerful source of motivation" (Maikel). "Teaching language skills in a practical way is a good approach because it actually combines the language skills with other areas of expertise and thus enhances the professional profile of the student" (Roberquis). "It is very good for ESL students because it shows them that they can learn from any topic involving real life situations including the language" (Clara).

4. What potential problems do you associate with practical language skills teaching? "The problem of practical language teaching is that it should always be addressed to intermediate 
and advanced students. It should also include topics of interests to them. Otherwise it turns difficult to create the proper learning environment. It should also be mixed with traditional teaching styles because alone it does not meet all the students' needs" (Jorge, Yoennis). "A potential problem would be adjusting the content to be taught to students' proficiency levels of the foreign language, for example, giving a lecture about advanced mechanics to beginner students would not be accurate and would probably de-motivate the students" (Alberto). "A potential problem with practical language skills teaching would be the topic. The topic should fit the students' needs and interests as interesting topics would add value to the effective teaching of foreign languages" (Daniel). "A poor attention to language structure which is the key for the complete assimilation of linguistic competence" (Manuel).

5. What are your personal practical experiences with practical Language Skills Teaching -give some real life/practical examples/feedback on the course. Why did it work for you? Why did it not work for you? "Practical language teaching really works. For me the clearest example occurred when I was a student. I spend a year studying English at the university and then went to Canada for a training course of a month. The way I see it, I learned more language in that month than I did in one year studying at the university. In one month I experienced the context and the motivation to learn more very strongly." (Anelis). "Practical language teaching has always worked for me. I have been a teacher for more than 20 years and I have always included this approach on my courses, not alone though. Students tend to learn easily with this approach for it motivates them more than the traditional approaches, and also they get to learn a language but also a new topic of interest that serves their professional profile" (Jorge, Yoennis).

6. "Practical/contextual language skills teaching for me is the best from the students' point of view. My students always ask for this kind of class because it is more motivational for them and also it is easier for them to remember what they have learned as it is more easily associated to real life situations than, say, a purely grammar lesson" (Alberto). "In my experience practical language skills teaching is a powerful tool to support the teaching-learning process. A good example is the course we have just attended. We have learned a lot about new subject matters, for example, management, and at the same time we have learned a lot about the language such as vocabulary, use in context, pronunciation and the general culture of the language" (Maikel). "This course we have just received is the proof of the relevance of practical language skills teaching. We have learned many new things about the English language in context and at the same time we have learned about topics that are new to us and are useful" (Roberquis).

The focus group members identified that effective language teaching skills and the methods of teaching language teachers apply will lead to improved language proficiency levels of students, particularly at intermediate and advanced levels. They consider that knowledge of the words and vocabulary of a language on its own does not increase the proficiency levels of language students in that particular language. They suggest that the attitude of the teacher how they wish to pass on their extensive knowledge and practical experiences of a particular language are of paramount importance. For example, a good and competent car driver is more likely to teach someone else how to drive with competence if they have the right positive attitude towards teaching others how to become a good driver. In addition, language teachers need to consider 
new ways of passing on their knowledge and experience to others in such a way that students feel compelled to learn more and to drive themselves for higher levels of language proficiencies that they thought they could never achieve. Table 2 is a summary of the application and rankings of the examined language teaching skills set. Results from this research suggest that language teachers who adopt and apply these skills are more likely to increase the language proficiency levels of their students.

Table 2: Application and Ranking of the examined Language Teaching Skills Set

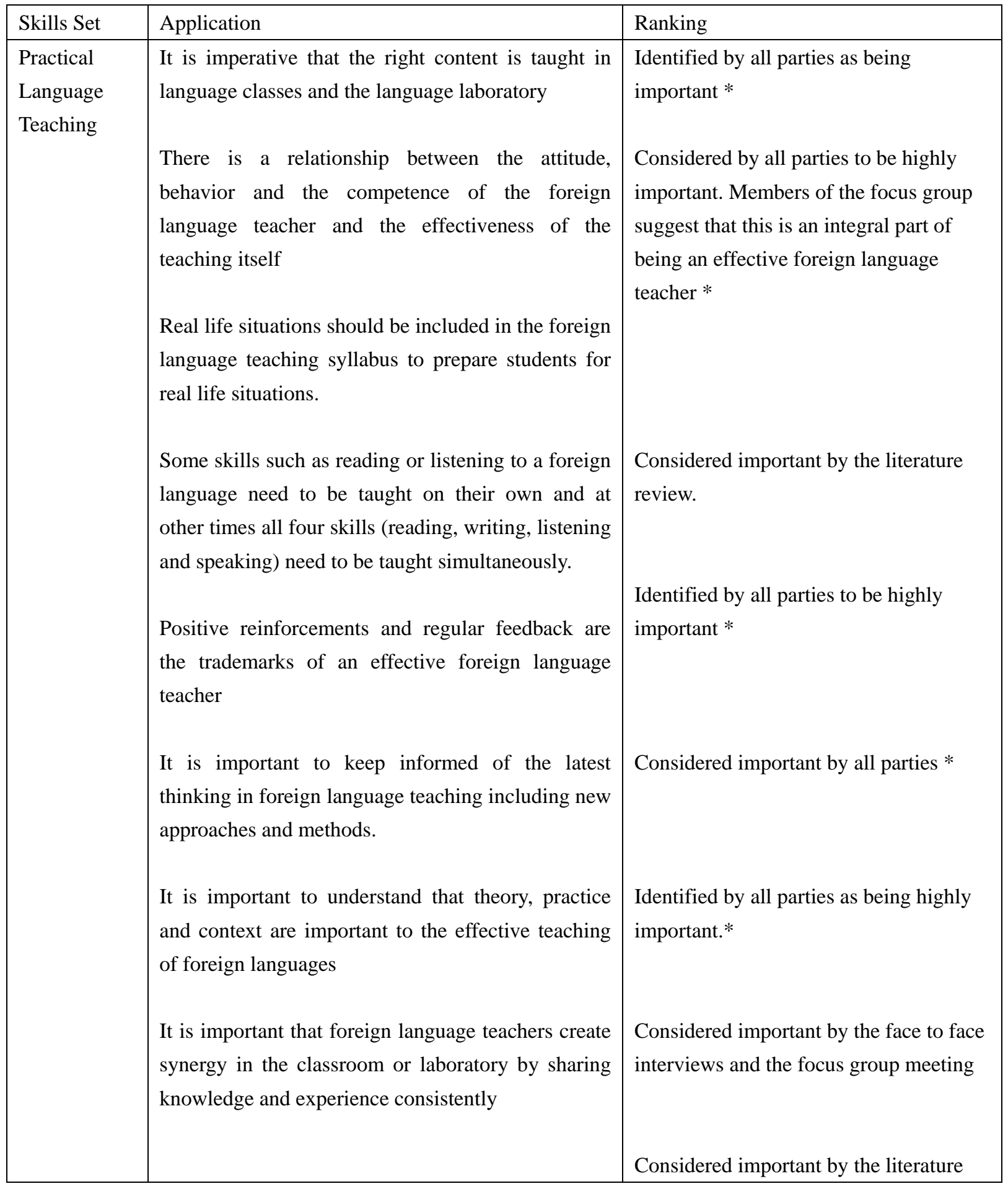


\begin{tabular}{|l|l|l|}
\hline & & review and face to face interviews. \\
\hline
\end{tabular}

*Literature review, face to face interviews and focus group meeting

It appears, based on the strength of evidence from the results of this research, that the language teaching skills of language teachers can be improved in a number of ways:

Develop 'Can Do' attitudes within students and drive them to higher language proficiency levels

Turn any negative attitudes towards more in depth learning into positive ones by selling the students the benefits for doing so

Convince students to try new ways of learning in both familiar and unfamiliar territories by changing their mind sets to put efforts where the greatest achievements can be made (*see below for an explanation of this $80 / 20$ rule by Pareto, adopted by Koch, 1988)

Search for new established or untried methods of teaching language skills, adopt/ adapt these and then make them fit for purpose for the UO

Invite more native language speakers from Universities and the Business World to improve the language proficiency levels of students in order to get them ready for the world that exists outside of the safe environment of the UO

Visit language teaching facilities in other countries and prepare proposals how to introduce new language teaching methods into the UO within current guidelines and budget limitations

*Koch (1998) suggests that the approach developed by the Italian economist and sociologist Vilifredo Pareto should be applied to become more effective and efficient in whatever people undertake to do. Koch questions the need to spend equal time on all work activities. To achieve, for example, higher levels of language proficiency, one should put one's efforts where the greatest achievements can be delivered. Koch suggests that $80 \%$ of what is important can be achieved with only $20 \%$ of effort (Fig.2).

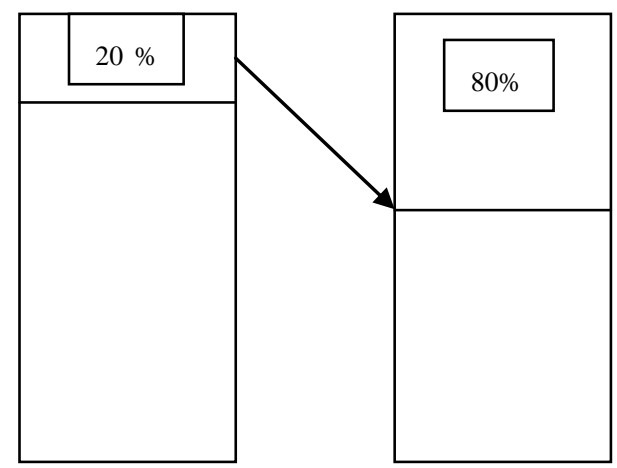

Inputs

Outputs

Causes

Consequences

Effort

Results 
Figure 2. The 80/20 Principle adapted from Koch (1998)

\section{Discussion}

The outcome of the literature review confirms that the ability to teach foreign languages on its own is not sufficient to increase the language proficiency levels of students and to maintain high levels of interest within students to immerse themselves more in foreign languages. It appears that students learn more effectively when a good learning climate has been created by their teachers in the classroom or language laboratory. The provision of "safe" working environments is vital as this enables students to practice and perfect their language skills. The most effective environments are those where making mistakes is considered to be a learning experience. The outcome from the face to face interviews and the focus group meeting provides new insights into what good language teaching looks like. Students at the UO benefit from being given some level of autonomy by their teachers to express themselves freely and being able to critically review the language teaching processes. Based on the strength of evidence from interviews, participants in the research consider that it is this level of personal involvement that increases motivation levels within students significantly.

Students and teachers would benefit from regular interactions with, for example, native English speakers who come from a variety of backgrounds such as business, education and non-profit organizations. This provides opportunities to learn new words and phrases but also to engage interactively, in another language, with subject matter experts who can share current best business practice across a number of industries. Students would be able to increase their knowledge how a business functions and operates. This will help them in their later life or career by being able to understand the perspectives of others better and gaining a deeper understanding of "where others are coming from or what is of value to others". In this respect, practice makes not only perfect but also helps to become a better translator or interpreter. Knowing the words of another language such as English is considered not sufficient. Attaching more meaning to words and expressions is far more effective and allows language students to become more proficient in new languages much faster and with better results. The UO is including translation and interpretation in its language teaching syllabus. Both are related to and dependent on psychological aspects. The UO is endeavoring to excel in these areas with a view to raise the language proficiency levels of its students whilst at the same time aiming to close the gap between linguists and psychologists (Section 1.2) for the benefit of foreign language teachers and students. This is encouraging.

The three hypotheses of this research are supported by strength of evidence from the literature review, face to face interviews and the focus group meeting (see Table 3 for a summary of the results), namely:

H1: English language students improve their English language proficiency substantially if they 
interact regularly with business people and academics whose native language is English. This hypothesis holds true. High levels of exposure to native English or other language speakers will increase foreign language proficiency levels in accordance with the levels of exposure to the foreign language. Language schools should consider adopting this approach.

$\mathrm{H} 2$ : English language teachers improve the quality of their teaching in the classroom for the benefits of students if they develop a positive and proactive attitude towards contemporary foreign language teaching methods and tools. This is a valid premise. The latest thinking in language teaching is based on years of research and feedback from practitioners in the field. Language teachers and language schools need to keep themselves abreast of new developments in this area and consider these for use in the classroom or language laboratory.

H3: English language teachers who give students the freedom to learn and practice using their own chosen topics are increasing students' self-confidence and speaking abilities of speaking in the foreign language substantially. This is a true hypothesis. Teachers who give students freedom to choose their own topics increase their motivation levels significantly which leads to higher levels of language proficiency.

Table 3. Hypotheses and Research Questions: Summary of Results

\begin{tabular}{|c|c|c|}
\hline Hypothesis & Related Research Question(s) & Results \\
\hline $\begin{array}{l}\text { H1: English language students } \\
\text { improve their English language } \\
\text { proficiency substantially if they } \\
\text { interact regularly with business } \\
\text { people and academics whose } \\
\text { native language is English. }\end{array}$ & $\begin{array}{l}\text { 1. What is the value of presenting } \\
\text { topics of interest by visiting } \\
\text { native English language } \\
\text { practitioners who use } \\
\text { contemporary English that is used } \\
\text { in business and academic } \\
\text { environments? } \\
3 \text {. Does the power distance } \\
\text { between English language } \\
\text { teachers and their students affect } \\
\text { the quality and proficiency levels } \\
\text { of the learning? }\end{array}$ & $\begin{array}{l}\text { The evaluation of the literature made } \\
\text { positive contributions to determine } \\
\text { whether exposure, for example, to } \\
\text { native English speakers would } \\
\text { enhance language proficiency to the } \\
\text { desired level. The face to face } \\
\text { interviews and focus group meeting } \\
\text { concluded that students who interact } \\
\text { regularly with business and } \\
\text { academics are more likely to develop } \\
\text { stronger language proficiency levels. } \\
\text { They will also increase their } \\
\text { understanding how businesses across } \\
\text { a number of industries function and } \\
\text { operate. }\end{array}$ \\
\hline $\begin{array}{l}\text { H2: English language teachers } \\
\text { improve the quality of their } \\
\text { teaching in the classroom for the } \\
\text { benefits of students if they } \\
\text { develop a positive and proactive } \\
\text { attitude towards contemporary } \\
\text { foreign language teaching } \\
\text { methods and tools. }\end{array}$ & $\begin{array}{l}\text { 2. What is the value to English } \\
\text { language teachers of conducting } \\
\text { regular research in order to keep } \\
\text { abreast of the latest thinking in } \\
\text { language teaching approaches and } \\
\text { methods? } \\
\text { 3. Does the power distance } \\
\text { between English language } \\
\text { teachers and their students affect } \\
\text { the quality and proficiency levels } \\
\text { of the learning? }\end{array}$ & $\begin{array}{l}\text { The literature provided some valid } \\
\text { and reliable evidence that suggests } \\
\text { that English language teachers who } \\
\text { are striving to keep abreast of the } \\
\text { latest thinking in foreign language } \\
\text { teaching, are improving the language } \\
\text { efficiency of their students. The } \\
\text { outputs from the face to face } \\
\text { interviews and the focus group } \\
\text { meeting strengthened the findings } \\
\text { from the literature review. }\end{array}$ \\
\hline
\end{tabular}


H3: English language teachers who give students the freedom to learn and practice using their own chosen topics are increasing students' self-confidence and speaking abilities of speaking in the foreign language substantially.
3. Do proactive and interactive presentations in native English improve the language skills of students or do these divert from the syllabus?

5. What is the value of regular research to keep abreast of the latest thinking in language teaching approaches and methods?
The literature is positively conclusive that students would benefit from being given the freedom to choose their own topics, for example, for discussion in the classroom, as this increases their motivation level significantly.

\section{Conclusions}

The Faculty of Humanities at the UO has created an inclusive and participatory language learning environment in which students can apply, try, bring together and evaluate their knowledge of foreign languages in a safe and realistic real life setting. Academic staff and foreign language teachers are continuously striving to improve ways of teaching their students languages such as contemporary English. It is highly commendable, given the financial and resource constraints, that new research is planned in order to enhance the effectiveness of language teaching. The positive, proactive and "can do" attitudes of language teachers are of paramount importance. These are the driving forces behind motivating and keeping students interested in trying out new approaches to learning a foreign language. Tools and techniques are important, too, and latest technological developments should be considered for use in the classroom and language laboratory, depending on prevailing local circumstances. Teachers will engage more in trying to close the gap between the perspectives of linguists and psychologists for the benefit of those who are going to learn languages. It is anticipated that teachers will become more actively engaged by conducting more teacher-initiated research into teaching methods and practices by, for example, spending more time in language learning facilities in other countries such as Belgium. The UO has recently engaged in some collaborative work with Flemish Universities in Belgium. Language teachers will attend workshops on current innovative teaching techniques including e-learning and other computer-based teaching methodologies.

A language laboratory will be created (language self access resource centre) for students to use current proactive and interactive techniques. Native English speakers are interacting with teachers and students in areas such as teaching and researching. There is conclusive evidence from the literature review, face to face interviews and the focus group meeting that language teaching skills and methods, when applied appropriately, can improve the people skills of language students as well as improve their self confidence levels, as shown by this study. One of the planned objectives is to teach English to all academic staff at the UO thus enhancing the professional profiles of all UO personnel. Insights and subject matter knowledge from a larger sample of students and practitioners of other Universities, including those in other countries, would have provided richer and diverse research data to address the research scope in more depth and universally. It is confirmed that the research scope from Section 1.3 has been 
answered and that all three hypotheses hold true and are valid in the context of this research. The authors suggest that more research and practical work needs to be conducted to close the perspective gap between linguists and psychologists in order to bring the two parties much closer together. New research should be considered in the area of developing multi-lingual and intercultural competence and their relationship.

\section{References}

Appel, J. (1995). Diary of a Language Teacher, Heinemann

Belyayev, B. V. (1969). Recent work on the psychology of language learning in The Psychological and Psycholinguistic Problems of Acquiring and Mastering a New Language, Moscow State University Press, pp. 145, 151, 152, 153

Belyayev, B. V. (1965). Brief Notes on the Psychology of Language Teaching, Moscow

Breen, M. (1987). Learner contribution to task design. In C. Candlin and D. Murphy (eds.), Language Learning Tasks (pp.23-46). EnglewoodCliffs, N.J.: Prentice Hall

Candlin, C., \& Murphy, D. F. (1987). Language learning tasks. Englewood Cliffs, NJ: Prentice Hall.

Celik, S. (2013). Unspoken social dynamics in an online discussion group: the disconnect between attitudes and overt behaviour of English language teaching graduate students, Educational Technology Research and Development, 61, 665-683, http://dx.doi.org/10.1007/s11423-013-9288-3

Doernyei, Z. (2009). The Psychology of Second Language Acquisition, Oxford University Press.

Ellis, R. (2003). Task-based language learning and teaching. Oxford: Oxford University Press.

Frydryclova Klimova, B. (2012). CLIL and the teaching of foreign languages, Social and Behavioral Sciences, 47, 572-576, Elsevier

Hismanoglu, M., \& Hismanoglu, S. (2011). Task-based language teaching: What every EFL teacher should do, Social and Behavioral Sciences, 15, 46-52, Elsevier

House, J. (2008). What is an Intercultural Speaker, in E. A. Soler's and M. P. S. Jorda'sIntercultural Language Use and Language Learning, Springer

Koch, R. (1998). The 80/20 Principle: The Secret of Achieving More with Less, New York Currency

Krashen, S. (1985). The Input Hypothesis: Issues and Implications, London: Longman

Lightbown, P. M., \& Spada, N. (2006). How Languages Are Learnt, Third Edition, Oxford University Press 


\section{Macrothink}

Business and Economic Research ISSN 2162-4860 2013, Vol. 3, No. 2

Littlewood, W. (1981). Communicative Language Teaching-An Introduction, Twelfth Printing 1990, Press Syndicate of the University of Cambridge

Long, M, \& Crookes, G. (1991). Three approaches to task-based syllabus design, TESOL Quarterly, 26(1), 27-56, http://dx.doi.org/10.2307/3587368

Lynch, T. (1996). Communication in the Language Classroom, Oxford University Press

Nunan, D. (1989). Designing tasks for the communicative classroom, Cambridge: Cambridge University Press.

Prabhu, N. (1987). Second language pedagogy, Oxford: Oxford University Press

Segalowitz, N. (2001). On the evolving connections between psychology and linguistics, Annual Review of Applied Linguistics, 21, 3-22, Cambridge University Press

Skehan, P. (1996). Task-based instruction, Annual Review of Applied Linguistics, 18, 268-286, http://dx.doi.org/10.1017/S0267190500003585

Soler, E. A. (2008). Linguistic Unity and Cultural Diversity in Europe: Implications for Research on English Language and Learning, in E.A. Soler's and M.P.S. Jorda's Intercultural Language Use and Language Learning, Springer

\section{Copyright Disclaimer}

Copyright reserved by the author(s).

This article is an open-access article distributed under the terms and conditions of the Creative Commons Attribution license (http://creativecommons.org/licenses/by/3.0/). 